\title{
Li-Ion Battery Fire Hazards and Safety Strategies
}

\author{
Lingxi Kong ${ }^{1}{ }^{(1)}$, Chuan $\mathrm{Li}^{2}$, Jiuchun Jiang ${ }^{3}$ and Michael G. Pecht ${ }^{1, *}$ \\ 1 Center for Advanced Life Cycle Engineering (CALCE), University of Maryland, College Park, MD 20742, \\ USA; lkong@umd.edu \\ 2 National Research Base of Intelligent Manufacturing Service, Chongqing Technology and Business \\ University, Chongqing 400067, China; chuanli@ctbu.edu.cn \\ 3 National Active Distribution Network Technology Research Center, Beijing Jiaotong University, \\ Beijing 100044, China; jcjiang@bjtu.edu.cn \\ * Correspondence: pecht@calce.umd.edu; Tel.: +1-301-405-5323
}

Received: 1 August 2018; Accepted: 18 August 2018; Published: 22 August 2018

\begin{abstract}
In the past five years, there have been numerous cases of Li-ion battery fires and explosions, resulting in property damage and bodily injuries. This paper discusses the thermal runaway mechanism and presents various thermal runaway mitigation approaches, including separators, flame retardants, and safety vents. The paper then overviews measures for extinguishing fires, and concludes with a set of recommendations for future research and development.
\end{abstract}

Keywords: Li-ion battery; energy conversion and storage; fire incidents; safety issues; separator shutdown; flame retardants; venting

\section{Introduction}

Li-ion batteries have become the first choice for applications that require rechargeable batteries. Compared with previous rechargeable batteries such as lead-acid batteries [1], Li-ion batteries have higher specific capacity, energy density, and power density. These advantages allow Li-ion batteries to support long-term operation and high-current usage, which are required by many of today's portable electronic devices, including cell phones, computers, and electric vehicles. However, Li-ion batteries present safety concerns. If the Li-ion battery is short-circuited or exposed to high temperature, exothermic reactions can be triggered, resulting in a self-enhanced increasing temperature loop known as "thermal runaway" that can lead to battery fires and explosions.

There have been numerous incidents of Li-ion batteries catching fire and exploding. For example, the United States (U.S.) Federal Aviation Administration (FAA) reported 206 air/airport Li-ion battery fire/explosion incidents from March 1991 to January 2018 [2]. In May 2011, a Chevrolet Volt caught fire three weeks after a crash test [3]. In 2013, several Tesla Model S sedans caught fire after they were damaged by road debris. Although Tesla strengthened the battery shield on its new and existing cars, in August 2016, a Tesla electric car caught fire in France during a promotional tour. In 2016, 92 Samsung Note 7 smartphones caught fire and caused a mass product recall [4]. Other Li-ion battery-powered devices have also been mentioned in fire-type incidents, such as notebook computers [4,5], hoverboards [4], and electronic cigarettes [6,7]. The corresponding causes for the Li-ion battery incidents vary. Short circuits, mechanical abuse, battery overcharging, and design and manufacturing flaws can all result in a battery fire/explosion. Saxena et al. [8] investigated e-cigarette incidents and found that the e-cigarette market is not regulated. Low-quality or even defective batteries are entering the market, which increases the risk of Li-ion battery explosions.

In conventional Li-ion batteries with liquid electrolytes, there are five key components: anode, cathode, separator, current collectors, and electrolyte. Among these components, the separator and the electrolyte are less tolerant to increasing temperature than the electrodes and current collectors, 
which are made of metal oxide/graphite or metal. A Li-ion battery uses a polymer separator and a flammable electrolyte, which are both constrained to certain temperature limits for safe performance.

When a Li-ion battery's temperature increases to approximately $130-150{ }^{\circ} \mathrm{C}$, the high-energy materials and the organic components are not stable and are prone to generate more heat [9]. If the generated heat does not dissipate, the battery temperature will further increase and accelerate the heat-releasing process. Thermal runaway may be triggered if a battery has certain defects that can lead to short-circuiting, is overheated, is subject to high pulse power usage, or is punctured. Generally, the passivation layer (solid electrolyte interphase, SEI) on the electrode decomposes at around $69^{\circ} \mathrm{C}$ [10]. After the breakdown of the SEI layer, the electrolyte reacts with the electrode and releases flammable hydrocarbon gases [11]. The polymer separator melts when the temperature is around $130{ }^{\circ} \mathrm{C}$ [9]. At higher temperatures, the positive electrode decomposes and releases oxygen.

Thermal runaway can be mitigated by methods that take effect at different stages of the thermal runaway process. These measures can be classified into three categories based on their effects on the process. In general, the potential for thermal runaway is influenced by the state of charge, operation conditions, battery electrode materials, electrolyte, and separator. The first category is preventive measures, wherein flame retardants are added for battery thermal stability. The second category is fail-safe measures that stop or decrease the damage caused by thermal runaway; these include separator shutdown and cell venting. The third category involves measures for extinguishing Li-ion battery fires once the thermal runaway has occurred.

This paper is organized as follows. Section 2 summarizes battery behavior during the thermal runaway process. Section 3 discusses measures for preventing thermal runaway. Section 4 overviews the use of flame retardants. Section 5 presents current methods and regulations for cell venting. Strategies and standards for putting out Li-ion battery fires are summarized in Section 6 . The conclusions and recommendations are presented in Section 7.

\section{The Thermal Runaway Process}

This section discusses how thermal runaway influences battery behavior. The thermal runaway process affects the battery voltage, temperature, and pressure. The battery voltage drops sharply before thermal runaway due to the delamination of the battery electrodes. The battery temperature increases because the heat generation rate overwhelms the heat dissipation rate. In addition, due to the reactions among battery active materials, organic electrolyte evaporation and gas generation lead to an accumulation of gases in the battery.

Under normal operation conditions, the battery open circuit voltage (OCV) does not drop sharply, whereas a sharp voltage drop indicates the loss of battery integrity and internal short circuit $[12,13]$. Al Hallaj et al. [12] conducted thermal runaway tests on Sony 18650 cells and found that the sharp voltage drop occurred around the separator melting point. However, Feng et al. [13] found the sharp voltage drop occurred only 15-40 s ahead of the uncontrolled temperature increase. This voltage drop phenomenon is not suitable as a warning signal that immediate action is required to prevent thermal runaway. In addition, before the voltage drop, the voltage remains almost unchanged and does not reveal the thermal runaway process in the initial stage. In order to characterize battery behavior during the entire thermal runaway process, it is necessary to track the battery temperature change.

The thermal runaway process can be triggered by high temperature, and there is a thermal runaway onset temperature above which the battery temperature will uncontrollably increase. Temperature values that indicate the onset of thermal runaway have been reported. Al Hallaj et al. [12] measured the onset of thermal runaway at $104^{\circ} \mathrm{C}, 109^{\circ} \mathrm{C}$, and $144{ }^{\circ} \mathrm{C}$, where the differences were related to various battery OCVs. The thermal runaway onset temperature is influenced by not only the battery $\mathrm{OCV}$, but also the type of battery cathode material. For commercially available cathode materials, their oxidation ability follows the order of $\mathrm{LiCoO}_{2}>\mathrm{LiMn}_{2} \mathrm{O}_{4}>\mathrm{LiFePO}_{4}$ [14]. Their thermal stability follows the reverse order, and the order of the theoretical onset of thermal runaway is $\mathrm{LiCoO}_{2}<$ $\mathrm{LiMn}_{2} \mathrm{O}_{4}<\mathrm{LiFePO}_{4}$. The reported thermal runaway onset temperature for $\mathrm{LiFePO}_{4}$ is $246{ }^{\circ} \mathrm{C}$ [15]. 
A 3D model was built to verify the experimental results [15]. The model prediction agrees well with the oven test data.

The temperature distribution in a battery can be nonuniform, especially during the thermal runaway process. Feng et al. [13] measured the battery case temperature and the core temperature, and found that the temperature difference can be as high as $520^{\circ} \mathrm{C}$. The modeling result [16] also indicated the existence of temperature difference. Nonuniform temperature distribution indicates where the thermal runaway process is triggered. Thermal runaway can initiate at some spots and propagate to the entire battery; for example, the localized temperature of the initial spot for battery thermal runaway can be as high as $800^{\circ} \mathrm{C}$.

Gas generation can occur during both normal operation and thermal runaway, but the gas composition is different in each process. During normal operation, the generated gases are $\mathrm{CO}_{2}$, $\mathrm{CO}, \mathrm{CH}_{4}$, and $\mathrm{O}_{2}$ [17]. During thermal runaway, the generated gases are $\mathrm{H}_{2}, \mathrm{CO}_{2}, \mathrm{CO}, \mathrm{CH}_{4}, \mathrm{C}_{2} \mathrm{H}_{6}$, and $\mathrm{C}_{2} \mathrm{H}_{4}[18,19]$. The flammable hydrocarbons are usually related to the electrolyte involved in the battery system. The $\mathrm{H}_{2}$ generation is related to the thermal runaway process. During thermal runaway, toxic fluoroorganics can also be generated [20]. Battery aging can also influence the gas composition. Roth et al. [21] compared the change of gas composition from punctured cells before and after the aging process. The volume percentage of $\mathrm{CO}$ composition increased from $4.2 \%$ to $11.3 \%, \mathrm{CO}_{2}$ increased from $12.6 \%$ to $26.3 \%$, and oxygen increased from $0.1 \%$ to $1.7 \%$.

Thermal runaway propagation among a battery pack that includes several individual cells is also worth notice. Thermal runaway may initiate in a single cell and propagate to the other cells in the battery pack. In this case, two thermal runaway scenarios present. For the initial cell, the thermal runaway is internally induced, whereas the other cells are at risk of thermal runaway by heating from the outside. Feng et al. [22] conducted a thermal runaway test on a battery pack containing six pouch-shaped batteries stacked together. They induced thermal runaway by penetrating one of the batteries on the end with a nail, and found that the thermal runaway cell can heat the other cells from the side. In their work, the thermal runaway onset time is defined as the moment that the temperature increased at least $10{ }^{\circ} \mathrm{C}$ in a second, and it was found that the thermal runaway in the other cells started at a temperature only around $100{ }^{\circ} \mathrm{C}$. Enlarging the space between cells in a battery pack can decrease the probability of thermal runaway propagation [23]. Lamb et al. [24] found that the electrical connection on a battery pack can work as the thermal conducting pathway, and a battery pack with different electrical configurations presented different behaviors during the thermal runaway event. A battery pack in which six 18650 batteries were fully connected in series remained intact after the thermal runaway, but the other battery pack, which was fully connected in parallel, was destroyed.

Some of the above-mentioned features could be incorporated into the battery management system (BMS) to limit the battery operation condition within a safety range. For example, Guo et al. [15] built a battery thermal model with a finite element approach. Forgez et al. [16] built a thermal model for the cylindrical battery to predict the battery internal temperature with an accuracy within $1.5^{\circ} \mathrm{C}$. This model is not complex, which makes it promising to be used in the BMS. The other methods that can improve the intrinsic thermal stability of batteries will be discussed in the following sections.

\section{Preventing Thermal Runaway Using Separators}

The separator is one of the basic components of a Li-ion battery. The separator can be made of paper, gel, or polymer. Among these materials, the polymer separator is the most widely used in commercial Li-ion batteries. As mentioned, the separator is placed in the middle of the positive and negative electrodes inside a battery. From the battery operation perspective, a separator serves two functions: it prevents direct contact between the two electrodes, and it provides a pathway for the lithium ions. The separator is always made of insulation materials that will not cause an internal short circuit in the battery, and it has a porous structure that can absorb liquid electrolyte. Battery electrochemical reactions rely on this ionic pathway provided by the separator. The implementation of a polymer separator also improves Li-ion battery safety. Since a polymer separator has a porous 
structure, if the battery temperature increases to near the separator melting point, the separator pores will close. This pore closure process is referred to as "separator shutdown".

The separator shutdown blocks the pathway between the positive and negative electrodes, and stops the electrochemical reactions. The battery impedance will also usually increase during this process. In the shutdown process, the polymer separator will not collapse at once, which means that the separator shutdown will not fully stop all of the reactions immediately. As a direct result, the battery will not start to cool down immediately during the separator shutdown or even after the separator shutdown [25]. The temperature at which the separator shutdown will be activated depends on the separator melting point. For example, the polypropylene (PP) and polyethylene (PE) separators will melt around $160{ }^{\circ} \mathrm{C}$ and $140{ }^{\circ} \mathrm{C}$, respectively [25].

The separator needs to retain its integrity during the shutdown process. Otherwise, if the separator shrinks during the shutdown process, the blocked positive and negative electrodes will directly connect with each other and lead to internal short circuit [26]. At this stage, the advantage of the separator shutdown no longer exists. In a single-layer polymer separator using only one type of material, the shutdown temperature is close to the separator melting temperature, which only allows a narrow margin for the separator shutdown to function. Even if the separator shutdown works, the separator will also still melt and shrink, which makes it difficult for a single-layer polymer separator to maintain integrity. There are designs for triple-layered polymer separators where the PE single layer is sandwiched between two PP layers. This design provides a certain safety margin due to the difference in the melting points. Another approach to improve the separator safety is to use ceramic materials in the polymer separator. The ceramic/polymer composite separator has a higher melting temperature and is more thermally stable than the polymer separator [27].

\section{Fire Prevention Using Flame Retardants}

In the thermal runaway process, the heat-releasing reaction will lead to the battery temperature increase, and the gases accumulated inside the battery will cause the internal pressure to increase. In order to improve the battery safety and prevent an explosion, multiple safety mechanisms have been implemented. The electrolyte used in a Li-ion battery is a solution of solvent, inorganic lithium salt, and some additives. Since the operating voltage of a Li-ion battery is usually higher than $3 \mathrm{~V}$, the solvent in the cell is a nonaqueous organic liquid, which is typically a mixture of cyclic and acyclic carbonate solvents. Although cyclic solvents usually have a higher flash point than non-cyclic solvents, the latter are combustible due to their low flash point. For example, the flash points of diethyl carbonate (DEC), dimethyl carbonate (DMC), and methyl ethyl carbonate (EMC) are $33^{\circ} \mathrm{C}, 15^{\circ} \mathrm{C}$, and $22^{\circ} \mathrm{C}$, respectively [28]. The flammable organic electrolyte has the lowest thermal stability among all of the components. During the thermal runaway process, the electrolyte can release flammable gases and the cathode material can generate oxygen. Under this condition, the increasing Li-ion battery temperature makes the battery prone to catching fire.

Several methods to improve the thermal stability of the electrolyte have been proposed. One approach is to add flame retardants (FRs) to the electrolyte. The first requirement of the FR is that its flash points should be higher than the corresponding values of the above-mentioned acyclic solvents. Moreover, the implemented FRs should be inert and should not hinder the battery's performance and the electrochemical reactions inside it. Xu et al. [29] found that triethyl phosphate (TEP) and trimethyl phosphate (TMP) were unstable on the graphite electrode. Hexamethylcyclophosphate (HMPN) has a high melting point, but the viscosity is also high. Adding these FRs can undermine the battery's performance. In order to improve these shortcomings, $\mathrm{Xu}$ et al. [30] synthesized tris-(2,2,2-trifluoroethyl) phosphate (TFP), bis(2,2,2-trifluoroethyl)-methylphosphate (BMP), and (2,2,2-trifluoroethyl) diethyl phosphate (TDP). They investigated the flame-retarding ability and electrochemical properties of the three additives. It was found that all three additives maintain the electrolyte conductivity and have excellent electrochemical properties. $\mathrm{Xu}$ et al. found that TFP has the best overall performance compared to BMP and TDP. As an additive to the electrolyte, 
in order to improve the thermal stability of the electrolyte without hindering the cycling performance, the weight percentage of the flame retardant content is usually less than $20 \%$ [31]. Some optimum values of the flame retardant content are reported as follows: $10 \mathrm{wt} \%$ 1-butyl-1-methylpyrrolidinium hexafluorophosphate $\left(\mathrm{BMP}^{-\mathrm{PF}_{6}}\right.$ ) [32], $10 \mathrm{wt} \%$ cresyl diphenyl phosphate (CDP) [33,34], and 5-10 wt \% 4-isopropyl phenyl diphenyl phosphate (IPPP) [35]. Table 1 lists some FRs found in the literature.

Instead of adding FRs to the electrolyte directly, another strategy is to incorporate the FRs into the battery by confining them to the separator. The FRs in the separator are designed to be released at a certain temperature. For example, Liu et al. [36] built a nonwoven electrospun Li-ion battery separator that has thermal-triggered flame-retardant properties. The separator is made of electrospun microfiber that is specially designed with a core-shell structure. The core is made of triphenyl phosphate (TPP), which is an FR. The shell is made of poly(vinylidene fluoride-hexafluoropropylene) (PVDF-HFP), which is insoluble in the electrolyte, and can protect the core. The TPP has a melting point around $160{ }^{\circ} \mathrm{C}$, which corresponds to the early stage of combustion. Meanwhile, the PVDF-HFP will not influence the battery electrochemical reactions. Liu et al. [36] claimed that this design provides flame-retarding ability without hindering the battery's performance. When the battery temperature increases to the melting point of PVDF-HFP $\left(160^{\circ} \mathrm{C}\right)$, the encapsulated TPP FR will be released into the electrolyte. At room temperature (around $25^{\circ} \mathrm{C}$ ), $4 \% \mathrm{TPP}$ is in the electrolyte.

Several manufacturers offer TPP, TEP, and TMP FR products for batteries: Jiangsu Yoke Technology; Tianjin Shilianrui Zuran Material; Zhejiang Wansheng; Jinan Taixing Fine Chemicals; and Jiangsu Changyu Chemical Industry. The applications and limitations of these FR products are mentioned above.

Beyond adding FR to the electrolyte, another strategy to increase battery safety is to replace the current low flash point solvents with a high flash point electrolyte, which can make the electrolyte intrinsically inert to fire. Arbizzani et al. [37] mixed the hydrophobic ionic liquid $N$-butyl- $N$-methylpyrrolidinium bis(trifluoromethanesulfonyl)imide (Pyr14TFSI) with the conventional $\mathrm{EC}$ (ethylene carbonate):DMC (with $1 \mathrm{M} \mathrm{LiPF}_{6}$ ) electrolyte, and found that the battery thermal resistance can be improved. Some other researchers tried to eliminate the combustible vapor generation sources by implementing a solid-state electrolyte. Wang et al. [38] made a concentrated fire-extinguishing electrolyte with TMP as the solvent and $\mathrm{LiN}\left(\mathrm{SO}_{2} \mathrm{~F}\right)_{2}$ ( $\left.\mathrm{LiFSA}\right)$ as the lithium salt. The molar concentration of LiFSA is higher than $3 \mathrm{M}$. This electrolyte is nonflammable, and has the potential to work as a fire extinguisher to put out the fire on other battery components. However, the high-concentration electrolyte (HCE) has certain disadvantages such as high cost, high viscosity, and poor wettability [39]. Chen et al. [39] developed a localized high-concentration electrolyte (LHCE) by diluting the electrolyte (3.2 M LiFSI in TEP) with bis(2,2,2-trifluoroethyl) ether (BTFE). Their test results on lithium batteries proved that the electrochemical performance of the LHCE is better than the HCE.

Table 1. Some flame retardants from published research work.

\begin{tabular}{ccc}
\hline Abbrev. & Full Name & Ref. \\
\hline BMP-PF $_{6}$ & 1-Butyl-1-methylpyrrolidinium hexafluorophosphate & {$[32]$} \\
CDP & Cresyl diphenyl phosphate & {$[33]$} \\
DMMP & Dimethyl methyl phosphonate & {$[40]$} \\
DPOF & Diphenyloctyl phosphate & {$[41]$} \\
HMPN & Hexamethylcyclophosphazene & {$[29]$} \\
IPPP & 4-Isopropyl phenyl diphenyl phosphate & {$[35]$} \\
{$\left[\mathrm{NP}(\mathrm{OCH})_{2}\right]_{3}$} & Hexamethoxycyclotriphosphazene & {$[42]$} \\
TEP & Triethyl phosphate & {$[29]$} \\
TMP & Trimethyl phosphate & {$[43]$} \\
TMP(a) & Trimethyl phosphate & {$[43]$} \\
TMP(i) & Trimethyl phosphite & {$[44]$} \\
TPP & Triphenyl phosphate & {$[45]$} \\
TTMT & 2,4,6-Tris(trifluoromethyl)-1,3,5-triazine (TTFMT) & {$[46]$} \\
\hline
\end{tabular}




\section{Fire and Explosion Prevention Using Cell Venting}

Another strategy for improving battery safety is to add fail-safe mechanisms into the battery. Typically implemented fail-safe mechanisms include safety vents, thermal fuses, and shutdown separators. Safety vents are designed to release extra internal pressure and prevent the continuous increase of internal temperature. Once the temperature is beyond the separator shutdown working temperature range, the thermal runaway can continue. At this time, flammable gases from the battery materials, including organic electrolyte, will accumulate inside the battery. Allowing the gas accumulation may result in the rupture of the battery. A cell-venting mechanism is designed to reduce the battery's internal pressure and release the gases.

When the cell venting is activated, the accumulated gases inside a battery will burst out at once. With the safety vents, the battery internal gases are released in a controlled way rather than in an uncontrolled explosion. After the venting, not only can the gathered flammable gases be released, but a large amount of heat contained in the gases can also be released to the environment. Furthermore, venting can reduce the pressure applied on the battery separator and reduce the risk of battery internal short circuit. The concept of a battery vent aims to decrease the pressure built up in the thermal runaway process and prevent battery rupture. Based on the Institute of Electrical and Electronics Engineers (IEEE) standard for rechargeable batteries for cellular telephones [47], cell vents are suggested for cell phone batteries: "Cells shall be designed to include a consistent vent design or mechanism, for example, foil, edge, seam, or score. The vent mechanism shall be designed to minimize projectiles and maximize [the] retention of cell contents". For an 18650 type Li-ion battery, the thermal runaway can propagate to the entire battery in less than $2 \mathrm{~s}$ [26]. The battery internal pressure will build up in this short time frame. The vent design should be able to handle the corresponding gas flux. Mier et al. [48] found that not only gases vented, but also the electrolyte and even solids. They also observed a venting-generated shock wave at approximately Mach 1, which indicated the high rate of gas venting.

Based on patent information, cell venting designs vary among battery types. Usually, an 18650 battery has small vent "windows" in the positive terminal cap for releasing extra internal pressure, whereas a prismatic battery uses a fill hole as the battery vent [49]. For example, one vent design for 18650 batteries is a fragile cap that breaks when the critical pressure is reached [50]. The typical cap structure of an 18650 cylindrical battery is shown in Figure 1. The cap contains a vent disk that has scoring made in prior. If the battery internal pressure increased to a critical point due to the gas accumulation, the vent disk will break at the scoring and form a pathway for the gas venting. Another vent design for a cylindrical-shaped battery (not 18650) for e-cigarette usage simply uses a sealed pinhole as the vent, the original purpose of which is for electrolyte injection [51]. In either design, if the vents are clogged by battery materials during the venting process, the battery pressure will increase and result in an explosion [49]. Additionally, in the 18650 battery, Finegan et al. [52] found that not only the clogged vent, but also insufficient gas venting can lead to battery bursting. Some 18650 battery designs include a central mandrel for ensuring that the gas has an escape route. However, under the gas pressure, even the mandrel can move and puncture the battery cap, thereby becoming a high-speed projectile [52].

The International Electrotechnical Commission (IEC) [53] defines venting as "release of excessive internal pressure from a cell/battery in a manner intended by design to preclude rupture or explosion". However, there is no specific requirement for vent design in the IEC document. Based on the European Council for Automotive Research and Development (EUCAR) hazard levels and descriptions of Li-ion batteries, a Li-ion battery is classified as level 4 (venting) if there is no fire or flame, no rupture, or no explosion, and if weight loss is greater than or equal to the electrolyte weight [54]. Table 2 (modified from Ref. [54]) lists the eight hazard levels. The range of levels changes from zero to seven, with the severer situation at a higher level. The venting process is a critical point, and there is no flame at this level, which means that the flammable gases are released through the cell venting without ignition. In a worse case, the high-temperature flammable gases accumulated inside the battery ignite after venting. 


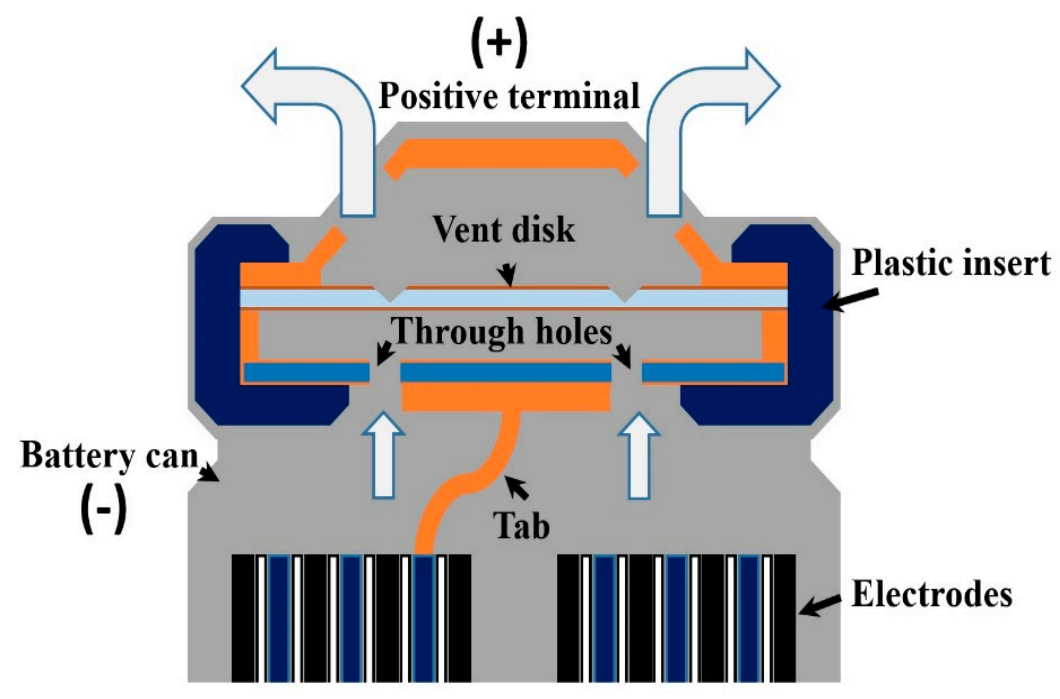

Figure 1. The typical structure of the 18650 battery cap. If the vent function works well during the thermal runaway process, the vent disk will break at the scoring and form a pathway to the internal gases.

Table 2. European Council for Automotive Research and Development (EUCAR) hazard levels and descriptions [54].

\begin{tabular}{|c|c|c|}
\hline Hazard Level & Description & Classification Criteria and Effect \\
\hline 0 & No effect & No effect. No loss of functionality. \\
\hline 1 & Passive protection activated & $\begin{array}{l}\text { No defect; no leakage; no venting, fire, or flame; } \\
\text { no rupture; no explosion; no exothermic reaction } \\
\text { or thermal runaway. Cell reversibly damaged. } \\
\text { Repair of protection device needed. }\end{array}$ \\
\hline 2 & Defect/damage & $\begin{array}{c}\text { No leakage; no venting, fire, or flame; no rupture; } \\
\text { no explosion; no exothermic reaction or thermal } \\
\text { runaway. Cell irreversibly damaged. Repair } \\
\text { needed. }\end{array}$ \\
\hline 3 & $\begin{array}{c}\text { Leakage } \\
\Delta \text { mass }<50 \%\end{array}$ & $\begin{array}{l}\text { No venting, fire, or flame* no rupture; no } \\
\text { explosion. Weight loss }<50 \% \text { of electrolyte weight } \\
\text { (electrolyte }=\text { solvent }+ \text { salt). }\end{array}$ \\
\hline 4 & $\begin{array}{c}\text { Venting } \\
\Delta \text { mass } \geq 50 \%\end{array}$ & $\begin{array}{l}\text { No fire or flame*; no rupture; no explosion. } \\
\text { Weight loss } \geq 50 \% \text { of electrolyte weight } \\
\text { (electrolyte = solvent }+ \text { salt). }\end{array}$ \\
\hline 5 & Fire or flame & No rupture; no explosion (i.e., no flying parts). \\
\hline 6 & Rupture & No explosion, but flying parts of the active mass. \\
\hline 7 & Explosion & Explosion (i.e., disintegration of the cell). \\
\hline
\end{tabular}

* The presence of flame requires the presence of an ignition source in combination with fuel and oxidizer in concentrations that will support combustion. Thus, if a spark source were added to the test configuration and the gas or liquid expelled from the cell was flammable, the test article would quickly progress from level 3 or level 4 to level 5 [54].

\section{Extinguishing Li-ion Battery Fires}

According to the National Fire Protection Association (NFPA), fires are classified into five different kinds (classes A, B, C, D, and K) (see Table 3 for the definitions) [55]. 
Table 3. Classification of fires [55].

\begin{tabular}{|c|c|}
\hline Class & Description \\
\hline A & Fires in ordinary combustible materials, such as wood, cloth, paper, rubber, and many plastics. \\
\hline B & $\begin{array}{c}\text { Fires in flammable liquids, combustible liquids, petroleum greases, tars, oils, oil-based paints, solvents, } \\
\text { lacquers, alcohols, and flammable gases. }\end{array}$ \\
\hline $\mathrm{C}$ & Fires that involve energized electrical equipment. \\
\hline $\mathrm{D}$ & Fires in combustible metals, such as magnesium, titanium, zirconium, sodium, lithium, and potassium. \\
\hline $\mathrm{K}$ & Fires in cooking appliances that involve combustible cooking media (vegetable or animal oils and fats). \\
\hline
\end{tabular}

The classification of a Li-ion battery fire can vary, but generally fits into classes A, B, or C. In some cases, a Li-ion battery is used as the power source, and the fire involves electrical devices. In other cases, a fire caused by a Li-ion battery can spread and ignite nearby materials. Fire extinguishers for Li-ion batteries vary based on the extinguishing agent, such as dry chemicals, carbon dioxide, foam, water, halons, and dry powders. Carbon dioxide can be used to suppress the fire, but it does not cool the battery down [56].

Putting out a Li-ion battery fire refers to both extinguishing the open flame and decreasing the battery temperature. If the battery temperature is high enough after the open flame is extinguished, there is still a possibility that the battery will reignite. In 2013, the Fire Protection Research Foundation conducted Li-ion battery fire testing on full-scale-model vehicles. In one of the tests, the battery reignited $22 \mathrm{~h}$ after the open flame was extinguished [57]. In 2017, there was a Li-ion battery fire incident in California involving an electric vehicle. The potential electrical hazard for the firefighters convinced them to use carbon dioxide fire extinguishers. Although the carbon dioxide extinguishers were successful, Andrew Klock, senior project manager at the NFPA, claimed that water would have worked to cool down the car and prevent reignition [58].

Current standards do not have specific requirements for extinguishing Li-ion battery fires. Standards for Li-ion batteries are published by the Institute of Electrical and Electronics Engineers (IEEE), Underwriters Laboratories (UL), and the United Nations (UN), but they focus only on battery abuse testing to ensure that $\mathrm{Li}$-ion batteries are safe during transportation. The tests are designed to be conducted under abusive conditions, such as crack, drop, shock, heating, and abnormal charging. This research gap forced the NFPA to conduct an assessment of Li-ion battery hazards [56]. The identified issues related to extinguishing Li-ion battery fires are: limited understanding of battery flammability, lack of fire protection specifications for battery packs, and unclear effectiveness of potential fire-extinguishing suppressants.

\section{Conclusions and Recommendations}

Numerous Li-ion battery fire and explosion incidents have attracted more and more attention to the issue of battery safety. This paper discussed three strategies for reducing the number of battery fire incidents: separator shutdown, flame retardants, and cell venting. Although the most widely used polymer separator has a shutdown function, once the separator shrinks and loses its integrity, the shutdown function is useless. As for flame retardants, the major issue is whether they hinder the battery's performance. Recent research showed the possibility of replacing the carbonate-based electrolyte with another organic electrolyte that has better thermal stability. The implementation of cell venting cannot guarantee that the heated battery content will be blocked inside the battery case during the thermal runaway. The battery venting design should consider blocking the heated battery content while releasing the accumulated gases. Lowering the gas release threshold or adding a screen on the vent can improve the venting function.

The strategies for extinguishing Li-ion battery fires were also discussed. Current available standards provide battery safety testing under abusive conditions, including electrical/mechanical/thermal abuse, but do not provide guidance for battery fire protection or 
extinguishing Li-ion battery fires. When extinguishing battery fires, cooling the battery is as important as suppressing the flame.

Author Contributions: Conceptualization, L.K. and M.G.P.; Writing-Original Draft Preparation, L.K. and M.G.P.; Writing-Review \& Editing, M.G.P., C.L. and J.J.; Supervision, M.G.P.

Funding: This research received no external funding.

Acknowledgments: The authors would like to thank the Center for Advanced Life Cycle Engineering (CALCE) at the University of Maryland, which is funded by more than 150 companies and organizations concerned with electronics reliability and safety. CALCE is a recipient of the NSF Innovation Award for its research into electronics reliability. The CALCE battery team explores battery design, test methods, life cycle reliability, and safety (See https:/ / calce.umd.edu/batteries).

Conflicts of Interest: The authors declare no conflict of interest.

\section{References}

1. Armand, M.; Tarascon, J.M. Building better batteries. Nature 2008, 451, 652. [CrossRef] [PubMed]

2. FAA Office of Security and Hazardous Materials Safety. Available online: https://www.faa.gov/about/ office_org/headquarters_offices/ash/ash_programs/hazmat/aircarrier_info/media/battery_incident_ chart.pdf (accessed on 9 July 2018).

3. Could Chevy Volt Lithium-Ion Battery Fires Burn out Interest in EVs and Hybrids? Available online: https://blogs.scientificamerican.com/observations/could-chevy-volt-lithium-ion-battery-firesburn-out-interest-in-evs-and-hybrids/ (accessed on 31 July 2018).

4. Can You Trust the Lithium-Ion Battery in Your Pocket? Available online: https:/ /www.washingtonpost. com/news/the-switch/wp/2016/09/16/can-you-trust-the-lithium-ion-battery-in-your-pocket/?utm_ term=.f7ae4130ed74 (accessed on 6 August 2017).

5. Why Lithium-Ion Smartphone Batteries Keep Exploding. Available online: http://globalnews.ca/news/ 1714748/why-lithium-ion-smartphone-batteries-keep-exploding/ (accessed on 6 August 2017).

6. Dramatic CCTV Footage Shows e-Cigarette Battery Exploding in Man's Pocket-Prompting Storage Warning from Fire Services. Available online: https://www.telegraph.co.uk/news/2016/12/22/dramatic-cctvfootage-shows-e-cigarette-battery-exploding-mans / (accessed on 31 July 2018).

7. Man Says e-Cigarette Battery Exploded in His Pocket. Available online: https:/ /www.cnn.com/2016/02/ 25/health/e-cigarette-explodes-in-mans-pocket/index.html (accessed on 6 August 2017).

8. Saxena, S.; Kong, L.; Pecht, M.G. Exploding E-cigarettes: A battery safety issue. IEEE Access 2018, 6, 21442-21466. [CrossRef]

9. Balakrishnan, P.; Ramesh, R.; Kumar, T. Safety mechanisms in lithium-ion batteries. J. Power Sources 2006, 155, 401-414. [CrossRef]

10. Wang, Q.; Sun, J.; Yao, X.; Chen, C. Thermal Behavior of Lithiated Graphite with Electrolyte in Lithium-Ion Batteries. J. Electrochem. Soc. 2006, 153, A329-A333. [CrossRef]

11. Spotnitz, R.; Franklin, J. Abuse behavior of high-power, lithium-ion cells. J. Power Sources 2003, 113, 81-100. [CrossRef]

12. Al Hallaj, S.; Maleki, H.; Hong, J.; Selman, J. Thermal modeling and design considerations of lithium-ion batteries. J. Power Sources 1999, 83, 1-8. [CrossRef]

13. Feng, X.; Fang, M.; He, X.; Ouyang, M.; Lu, L.; Wang, H.; Zhang, M. Thermal runaway features of large format prismatic lithium ion battery using extended volume accelerating rate calorimetry. J. Power Sources 2014, 255, 294-301. [CrossRef]

14. Kong, W.; Li, H.; Huang, X.; Chen, L. Gas evolution behaviors for several cathode materials in lithium-ion batteries. J. Power Sources 2005, 142, 285-291. [CrossRef]

15. Guo, G.; Long, B.; Cheng, B.; Zhou, S.; Xu, P.; Cao, B. Three-dimensional thermal finite element modeling of lithium-ion battery in thermal abuse application. J. Power Sources 2010, 195, 2393-2398. [CrossRef]

16. Forgez, C.; Do, D.V.; Friedrich, G.; Morcrette, M.; Delacourt, C. Thermal modeling of a cylindrical $\mathrm{LiFePO}_{4}$ /graphite lithium-ion battery. J. Power Sources 2010, 195, 2961-2968. [CrossRef]

17. Shin, J.S.; Han, C.H.; Jung, U.H.; Lee, S.I.; Kim, H.J.; Kim, K. Effect of $\mathrm{Li}_{2} \mathrm{CO}_{3}$ additive on gas generation in lithium-ion batteries. J. Power Sources 2002, 109, 47-52. [CrossRef] 
18. Golubkov, A.W.; Fuchs, D.; Wagner, J.; Wiltsche, H.; Stangl, C.; Fauler, G.; Voitic, G.; Thaler, A.; Hacker, V. Thermal-runaway experiments on consumer Li-ion batteries with metal-oxide and olivin-type cathodes. RSC Adv. 2014, 4, 3633-3642. [CrossRef]

19. Spinner, N.S.; Field, C.R.; Hammond, M.H.; Williams, B.A.; Myers, K.M.; Lubrano, A.L.; Rose-Pehrsson, S.L.; Tuttle, S.G. Physical and chemical analysis of lithium-ion battery cell-to-cell failure events inside custom fire chamber. J. Power Sources 2015, 279, 713-721. [CrossRef]

20. Hammami, A.; Raymond, N.; Armand, M. Lithium-ion batteries: Runaway risk of forming toxic compounds. Nature 2003, 424, 635-636. [CrossRef] [PubMed]

21. Roth, E.P.; Crafts, C.C.; Doughty, D.H.; McBreen, J. Advanced Technology Development Program for Lithium-Ion Batteries: Thermal Abuse Performance of 18650 Li-Ion Cells; Sandia Report; Sandia National Laboratories: Albuquerque, NM, USA, 2004.

22. Feng, X.; Sun, J.; Ouyang, M.; Wang, F.; He, X.; Lu, L.; Peng, H. Characterization of penetration induced thermal runaway propagation process within a large format lithium ion battery module. J. Power Sources 2015, 275, 261-273. [CrossRef]

23. Lopez, C.F.; Jeevarajan, J.A.; Mukherjee, P.P. Experimental analysis of thermal runaway and propagation in lithium-ion battery modules. J. Electrochem. Soc. 2015, 162, A1905-A1915. [CrossRef]

24. Lamb, J.; Orendorff, C.J.; Steele, L.A.M.; Spangler, S.W. Failure propagation in multi-cell lithium ion battereis. J. Power Sources 2015, 283, 517-523. [CrossRef]

25. Venugopal, G.; Moore, J.; Howard, J.; Pendalwar, S. Characterization of microporous separators for lithium-ion batteries. J. Power Sources 1999, 77, 34-41. [CrossRef]

26. Finegan, D.P.; Scheel, M.; Robinson, J.B.; Tjaden, B.; Hunt, I.; Mason, T.J.; Millichamp, J.; Michiel, M.D.; Offer, G.J.; Hinds, G.; et al. In-operando high-speed tomography of lithium-ion batteries during thermal runaway. Nat. Commun. 2015, 6, 6924. [CrossRef] [PubMed]

27. Orendorff, C.J. The role of separators in lithium-ion cell safety. Electrochem. Soc. Interf. 2012, 21, 61-65. [CrossRef]

28. Yuan, X.; Liu, H.; Zhang, J. Lithium-Ion Batteries: Advanced Materials and Technologies; CRC Press: Boca Raton, FL, USA, 2011; ISBN 9781439841280.

29. Xu, K.; Zhang, S.; Allen, J.L.; Jow, T.R. Nonflammable electrolytes for Li-ion batteries based on a fluorinated phosphate. J. Electrochem. Soc. 2002, 149, A1079-A1082. [CrossRef]

30. Xu, K.; Ding, M.S.; Zhang, S.; Allen, J.L.; Jow, T.R. Evaluation of fluorinated alkyl phosphates as flame retardants in electrolytes for Li-ion batteries: I. Physical and electrochemical properties. J. Electrochem. Soc. 2003, 150, A161-A169. [CrossRef]

31. Zhang, S.S. A review on electrolyte additives for lithium-ion batteries. J. Power Sources 2006, 162, $1379-1394$. [CrossRef]

32. Choi, J.A.; Sun, Y.K.; Shim, E.G.; Scrosati, B.; Kim, D.W. Effect of 1-butyl-1-methylpyrrolidinium hexafluorophosphate as a flame-retarding additive on the cycling performance and thermal properties of lithium-ion batteries. Electrochim. Acta 2011, 56, 10179-10184. [CrossRef]

33. Wang, Q.; Ping, P.; Sun, J.; Chen, C. Improved thermal stability of lithium ion battery by using cresyl diphenyl phosphate as an electrolyte additive. J. Power Sources 2010, 195, 7457-7461. [CrossRef]

34. Wang, Q.; Ping, P.; Sun, J.; Chen, C. Cresyl diphenyl phosphate effect on the thermal stabilities and electrochemical performances of electrodes in lithium ion battery. J. Power Sources 2011, 196, 5960-5965. [CrossRef]

35. Wang, Q.; Sun, J.; Yao, X.; Chen, C. 4-Isopropyl phenyl diphenyl phosphate as flame-retardant additive for lithium-ion battery electrolyte. Electrochem. Solid-State Letters 2005, 8, A467-A470. [CrossRef]

36. Liu, K.; Liu, W.; Qiu, Y.; Kong, B.; Sun, Y.; Chen, Z.; Zhuo, D.; Lin, D.; Cui, Y. Electrospun core-shell microfiber separator with thermal-triggered flame-retardant properties for lithium-ion batteries. Sci. Adv. 2017, 3, e1601978. [CrossRef] [PubMed]

37. Arbizzani, C.; Gabrielli, G.; Mastragostino, M. Thermal stability and flammability of electrolytes for lithium-ion batteries. J. Power Sources 2011, 196, 4801-4805. [CrossRef]

38. Wang, J.; Yamada, Y.; Sodeyama, K.; Watanabe, E.; Takada, K.; Tateyama, Y.; Yamada, A. Fire-extinguishing organic electrolytes for safe batteries. Nat. Energy 2018, 3, 22-29. [CrossRef]

39. Chen, S.; Zheng, J.; Yu, L.; Ren, X.; Engelhard, M.H.; Niu, C.; Lee, H.; Xu, W.; Xiao, J.; Liu, J.; Zhang, J.G. High-efficiency lithium metal batteries with fire-retardant electrolytes. Joule 2018, 2, 1-11. [CrossRef] 
40. Xiang, H.; Xu, H.; Wang, Z.; Chen, C. Dimethyl methylphosphonate (DMMP) as an efficient flame retardant additive for the lithium-ion battery electrolytes. J. Power Sources 2007, 173, 562-564. [CrossRef]

41. Shim, E.G.; Nam, T.H.; Kim, J.G.; Kim, H.S.; Moon, S.I. Diphenyloctyl phosphate as a flame-retardant additive in electrolyte for Li-ion batteries. J. Power Sources 2008, 175, 533-539. [CrossRef]

42. Lee, C.W.; Venkatachalapathy, R.; Prakash, J.A. novel flame-retardant additive for lithium batteries. Electrochem. Solid-State Lett. 2000, 3, 63-65. [CrossRef]

43. Yao, X.; Xie, S.; Chen, C.; Wang, Q.; Sun, J.; Li, Y.; Lu, S. Comparative study of trimethyl phosphite and trimethyl phosphate as electrolyte additives in lithium ion batteries. J. Power Sources 2005, 144, 170-175. [CrossRef]

44. Shim, E.G.; Nam, T.H.; Kim, J.G.; Kim, H.S.; Moon, S.I. Electrochemical performance of lithium-ion batteries with triphenylphosphate as a flame-retardant additive. J. Power Sources 2007, 172, 919-924. [CrossRef]

45. Kim, K.; Ahn, S.; Kim, H.S.; Liu, H.K. Electrochemical and thermal properties of 2, 4, 6-tris (trifluoromethyl)-1, 3, 5-triazine as a flame retardant additive in Li-ion batteries. Electrochim. Acta 2009, 54, 2259-2265. [CrossRef]

46. Nam, T.H.; Shim, E.G.; Kim, J.G.; Kim, H.S.; Moon, S.I. Diphenyloctyl phosphate and tris (2,2,2-trifluoroethyl) phosphite as flame-retardant additives for Li-ion cell electrolytes at elevated temperature. J. Power Sources 2008, 180, 561-567. [CrossRef]

47. Rechargeable Batteries for Cellular Telephones; IEEE Standard 1725; IEEE Power Engineering Society Press: New York, NY, USA, 2011.

48. Mier, F.A.; Morales, R.; Coultas-McKenney, C.A.; Hargather, M.J.; Ostanek, J. Overcharge and thermal destructive testing of lithium metal oxide and lithium metal phosphate batteries incorporating optical diagnostics. J. Energy Storage 2017, 13, 378-386. [CrossRef]

49. Chu, A.C.; Gozdz, A.S.; Riley, G.N., Jr.; Hoff, C.M. Battery Tab Location Design and Method of Construction. U.S. Patent US8084158B2, 27 December 2011.

50. Kaschmitter, J.L.; Martucci, F.L.; Mayer, S.T.; Souh, J.H.; Thompson, S. Cell Cap Assembly Having Frangible Tab Disconnect Mechanism. U.S. Patent 5,609,972, 11 March 1997.

51. Hua, J.; Yang, J. Mesoporous Lithium-Ion Battery Vented at Both Ends, and Method for Manufacturing Same. W.O. Patent 2,016,008,137, 21 January 2016.

52. Finegan, D.P.; Darcy, E.; Keyser, M.; Tjaden, B.; Heenan, T.M.M.; Jervis, R.; Bailey, J.J.; Vo, N.T.; Magdysyuk, O.V.; Drakopoulos, M.; et al. Identifying the cause of rupture of Li-ion batteries during thermal runaway. Adv. Sci. 2018, 5, 1700369. [CrossRef] [PubMed]

53. IEC Standard 62133. Secondary Cells and Batteries Containing Alkaline or Other Non-acid Electrolytes-Safety Requirements for Portable Sealed Secondary Cells, and for Batteries Made from Them, for Use in Portable Applications; IEC Standard 62133: Geneva, Switzerland, 2012.

54. Josefowitz, W.; Kranz, H.; Macerata, D.; Soczka-Guth, T.; Mettlach, H.; Porcellato, D.; Orsini, F.; Hansson, J. Assessment and Testing of Advanced Energy Storage Systems for Propulsion-European Testing Report. In Proceedings of the 21st Worldwide Battery, Hybrid and Fuel Cell Electric Vehicle Symposium \& Exhibition, Monte Carlo, Monaco, 2-6 April 2005.

55. National Fire Protection Association. Portable Fire Extinguishers; National Fire Protection Association: Quincy, MA, USA, 2013.

56. Mikolajczak, C.; Kahn, M.; White, K.; Long, R.T. Lithium-ion Batteries Hazard and Use Assessment; Springer Science \& Business Media Press: New York, NY, USA, 2012, ISBN 978-1-4614-3485-6.

57. Long, R.T.; Blum, A.F.; Bress, T.J.; Cotts, B.R. Best Practices for Emergency Response to Incidents Involving Electric Vehicles Battery Hazards: A Report on Full-Scale Testing Results; National Fire Protection Research Foundation: Quincy, MA, USA, 2013.

58. Lithium-Ion Battery Car Fires Pose A New Challenge for Firefighters. Available online: http:/ / www.rightinginjustice.com/news/2017/02/06/lithium-ion-battery-car-fires-pose-a-newchallenge-for-firefighters / (accessed on 6 August 2017).

(C) 2018 by the authors. Licensee MDPI, Basel, Switzerland. This article is an open access article distributed under the terms and conditions of the Creative Commons Attribution (CC BY) license (http://creativecommons.org/licenses/by/4.0/). 